Pedro Coura-Filho 1

\section{Distribuição da esquistossomose no espaço urbano. 2. A proximação teórica sobre a acumulação, concentração, centralização do capital e a produção de doenças}

\author{
Schistosomiasis mansoni in urban territory. \\ 2. A theoretical approach to the accumulation, \\ concentration, and centralization of capital \\ and the production of disease
}

1 Centro de Pesquisas René Rachou, Fundação Oswaldo Cruz. Av. Augusto de Lima 1715, C. P. 1743 , Belo Horizonte, MG 30190-002, Brasil.

\begin{abstract}
A bstract This study discusses the urbanization of schistosomiasis in the Greater Metropolitan Area of Belo Horizonte, Minas Gerais, Brazil. The observation that schistosomiasis has become endemic in an urban area is discussed using the concept of social organization of space as an exercise in providing an operational basis for the social and environmental paradigms of collective health. Elements from the new world economic order are discussed: the concept of socially constructed space, the internationalization of capital, the periphery, and the resulting collective disease generation process. Due to the deterioration of state health services and the logic of the new world economic order, the need for local schistosomiasis control solutions is stressed.

Key words Schistosomiasis; Urbanization; Epidemiology; Public Health

Resumo Neste estudo são discutidos dados sobre a urbanização da esqui stossomose na Região Metropolitana de Bel o Horizonte, MG, Brasi I. A endemização da esquistossomose em área urbana é discutida usando-se a categoria organização social do espaço como exercíci o de operacionalização entre o paradígma ambiental e o social em saúde coletiva. São abordados el ementos presentes na nova ordem econômi ca mundial, concepção de espaço socialmente construído, mundiali zação do capital, periferia e conseqüente processo coletivo de produção de doenças. Diante do desmantel amento dos servi ços de saúde do Estado e da lógi ca da nova ordem econômica mundial, é reforçada a busca de soluções locais para o controle da esqui stossomose. Palavras-chave Esquistossomose; Urbanização; Epidemiologia; Saúde Pública
\end{abstract}




\section{Introdução}

Para entendermos a urbanização da esquistossomose como um novo desafio para os serviços de saúde, é preciso considerar que o enfoque clínico produziu atenção individual explorada pelo ato médico como mercadoria e o controle social, exercido pelo Estado. Embora este paradígma tenha produzido tecnologia para atender indivíduos (medicamentos, insumos clínico-hospitalares através de um sistema de serviços centralizado, pelo Estado), ele não conseguiu reduzir o risco de adoecer e morrer, nem mesmo das doenças preveníveis.

No caso do paradigma social, produziu fundamentação teórico-conceitual para explicar processos coletivos de produção de doenças, além de ter servido de espaço de resistência de sanitarista e da comunidade civil, no período autoritário brasileiro. Sua limitação foi não estabelecer operacionalidade para o sistema de prestação de serviços.

O perfil clínico-epidemiológico produzido pela nova ordem mundial do capital cria um novo desafio para se articular conhecimentos acumulados pelos paradigmas ambiental e social, visando a maior operacionalização dos serviços. Perspectivas promissoras são elaboradas no sentido de apontar outras categorias mediadoras entre estes paradigmas, tais como, o desgaste no trabalho, organização social do espaço e a organização da sociedade civil com a científica, cada vez mais crescente em torno de demandas urgentes (água, esgoto, educação, segurança, cidadania, etc.), permitindo elaboração de valores universais tais como ecologia, cidadania, direito humano e moralidade da "coisa pública", iniciando assim um alfabeto ético mundializado. Experiências conjuntas de técnicos dos serviços, academia e intelectuais e sociedade civil organizada têm apontado para a possibilidade operacional no planejamento de serviços de saúde auto-referido (Tognoni, 1993; Valla, 1993).

O entendimento da produção das desigualdades sociais devido ao desenvolvimento econômico aponta a forma de produção, o consumo e a distribuição diferenciada de produtos, como elementos que precisam ser compreendidos dentro da concepção do capital móvel. Este, constrói demandas e produtos em territórios virtuais. Devido a ele, o conceito de espaço ganha maior flexibilidade, não sendo mais o lugar fixo como concebido na epidemiologia clínica de Estado, centrada em fatores de risco, na medicalização de indivíduos “doentes" e no controle social. Nesta concepção, a teoria de foco ganha concepção de espaço social; a perife- ria, de mercado móvel; as doenças endêmicas, de conseqüências de um modo de vida de excluídos da produção e do consumo; e, conceito de determinação para receptividade.

Compreender os novos processos de produção de doenças urbanas como no caso da esquistossomose exige assumir que o desenvolvimento/subdesenvolvimento não pode ser mais visto como conseqüência do capital acumulado, mas como sua principal estratégia. A má qualidade de vida é sistematicamente produzida no tempo e lugar que interessa o capital, e os novos processos de produção de endemias são reflexos desta estratégia que não incomoda o capital, pelo contrário, são produzidos para garantir sua sobrevivência e seu crescimento global.

Com este entendimento, é utopia pensar em programas com medidas padronizadas para controlar endemias, como a esquistossomose, que é recorrente em vastas regiões onde residem a maioria dos excluídos. A possibilidade e responsabilidade de minimizar o risco de adoecer e morrer é um "direito" remetido ao "cidadão" em nível local; desde que ocorram sociedades organizadas, politicamente determinadas e tecnicamente capacitadas para gerenciar ações e programas conforme características particulares; porque não será o Estado reduzido, preconizado pela nova ordem mundial, que vai assumir sozinho este compromisso com eficiência.

A compreensão da causalidade das doenças parasitárias que estabel ece relação entre hospedeiro, agente etiológico e o homem, permite estabelecer ações de controle visando à eliminação do hospedeiro intermediário ou do parasita no homem. Neste modelo, o homem e o seu tipo de relação com o meio ambiente é apontado como determinante de uma probabilidade de adoecer e morrer (Rosicky, 1987), dependendo do modo e da intensidade de transmissão da infecção, da resistência imunológica do infectado e da adaptação parasita/homem (Bradley, 1972). As ações de cura sugeridas a partir deste modelo visam ao tratamento quimioterápico e à recuperação clínica dos indivíduos infectados; portanto, são ações que visam à interrupção da doença (atenção secundária) e à intervenção cirúrgica nos casos graves (atenção terciária). Este modelo pressupõe que as causas de transmissão das parasitoses são ambientais, que o agravo é condicionado por condutas individuais (fatores de risco) e que o controle também deve ser individualizado.

Com a revolução industrial construindo aglomerações de trabalhadores vivendo sob 
precárias condições de vida, devido à baixa remuneração da força de trabalho, a ocorrência de doenças passou a ter um componente de determinação coletiva devido ao modo de produção. Foram centralizados os meios de produção industrial e socializados os modos de adoecer, aumentando a possibilidade de maior número de indivíduos adoecerem pelas mesmas causas, nos mesmos locais de trabalho e/ ou residência. Nestas condições, são formados focos de alta transmissão de parasitoses, exigindo ações abrangentes no meio ambiente. As causas e as ações exigi das para o controle de doenças passaram a ser entendidas como sendo de individuais a coletivas, visto que sua determinação tomou dimensão de processo social (Stark,1977).

A insuficiência tecno-operacional dos modelos ambiental e social tem sido questionada em função de novas características das formas atuais de se conceber modo de vida urbano, nova ordem econômica, desenvolvimento, relações de capital/espaço, indivíduo/sociedade, informação/ comunicação, com novos processos de (re)produção de velhas e novas endemias. Endemia aqui (re)conceituada como:

“expressão no nível coletivo de processo saúde-enfermidade, consistindo no conjunto estruturado de processos determinantes de uma doença, em unidades espaciais particulares de uma formação econômico-social" (Sabroza, 1992:241).

Partindo deste conceito de endemia, discutiremos neste estudo a "organização social do espaço" como uma categoria mediadora entre a explicação dos determinantes macrossociais e sua externalidade em doenças individuais; além de discutir outros elementos que o compõem, tais como: uso e valor da terra, estratégia do capital móvel, os circuitos econômicos de produção e distribuição do capital no espaço urbano, nova ordem econômica mundial e seus reflexos na produção de doenças em países de terceiro mundo assim como a função do Estado reduzido visando contribuir no entendimento de novos processos de receptividade e determinação desta velha endemia.

Embora a categoria organização social do espaço apresente dificuldades metodológicas de uso e justificativa, torna-se urgente sua elaboração, assim como outras categorias, devido ao desmantelamento dos serviços centrais do Estado, balizado na descentralização para o nível local despreparado técnica e gerencialmente para exercer demandas crescentes de endemização de doenças tidas como tipicamente rurais e que vêm se urbanizando.
A cumulação, concentração, centralização do capital e a produção de doenças no espaço urbano

A teoria psicogenética do desenvolvimento cognitivo tem sido usada como analogia para se compreender o processo de construção do conhecimento. Na estruturação de conhecimentos sobre a realidade sugere-se partir da descrição minuciosa do objeto "em si" para depois estabelecer sua relação com outros, levando ao entendimento da complexidade que o envolve. Para Garcia (1986), na elaboração de uma aproximação teórica é fundamental que bases conceituais sejam capazes de descrever o objeto, de historicizar seu processo evolutivo enquanto singularidade que estabelece relações no âmbito particular e explicar sua ocorrência. Recomenda, também, identificar características de estabilidade e instabilidade da própria estrutura das relações das informações que, em determinado momento histórico, necessita ser desestruturado para ser reestruturado visando incorporar elementos novos que a realidade necessariamente imprime em sistemas complexos. Um marco teórico seria um arcabouço de informações vindas da realidade com a função de compreender a totalidade, mesmo que provisória. Pressupõe dar conta de responder a pergunta condutora e as subperguntas articuladas com a realidade; e que, neste processo, outras perguntas podem surgir devido à instabilidade das relações dos fatos dentro do processo de estruturação/ desestruturação do conhecimento. No confronto da verdade e da certeza provisória, as dimensões de tempo e espaço são escalas que definem certa coerência interna na estrutura do conhecimento, conforme sua dinâmica e estado em um dado momento. O processo que produz a estrutura determinante de uma dada realidade compõe um sistema de informações que será dissipativo, se não for histórico, dinâmico, instável e acumulativo. A consistência interna de um marco teórico pressupõe o alargamento da visão baseado em informações acumuladas. Acumulações estas real izadas pelo observador e não por simples superposição de visões por vários observadores produzindo informações em tempo, espaço e visões diferentes. As experiências interdisciplinar e transdisciplinar podem contribuir fornecendo informações conjuntas advindas de várias áreas do saber organizado. Mas, a simples superposição de informações sobre a realidade pode no máximo produzir visão reducionista, e, conseqüentemente, esvaziar a potência que a informação pode exercer, para produzir conhecimento no- 
vo e fazer do objeto e do sujeito um sistema acumulativo retro-alimentado.

Não há objeto sem sujeito em um sistema acumulativo complexo, principalmente se se considera a produção de conhecimento como possível de ser impregnada de algum nível de ideologia imposta pelo sujeito. Mas, o real, embora admitido como instável e sem relações fixas, também apresenta mecanismos próprios de modulação, garantindo sua consistência interna; senão seria dissipativo e a teoria não teria função explicativo-operacional, mesmo que provisória (Maturana, 1974).

Fazendo uso destas premissas e procurando aqui elaborar uma aproximação teórica sobre a organização social do espaço, torna-se necessário entender algumas carterísticas do espaço, tais como: a "distribuição, evol ução histórica e especifici dades sóci o-político-culturais" (Smith, 1988).

A geografia clássica se ocupou em entender a distribuição da ocupação do solo pelo homem através de sua relação direta de exploração da natureza. As formas desta relação Homem/Natureza $(\mathrm{H} / \mathrm{N})$ deixaram na natureza as marcas distintas no tempo e no espaço. Observa-se que, dos aglomerados de indivíduos para troca de mercadorias (era mercantilista), do início da industrialização até o século XVI (era industrial) e após a Il guerra mundial (era tecnológica), podemos identificar três tipos de organizações das cidades. O primeiro período (mercantilista) produziu a cidade molecular, cuja função básica era administrativa e comercial. Tinha como principal problema a falta de consumidores. O segundo período (industrial) produziu crescimento dos aglomerados já existentes e migração do homem rural para o espaço urbano, configurando assim a presença do Estado modulador do fluxo de capital. A colonização e as guerras foram estratégias eficientes neste período, promovendo circulação do capital, criando produtos e demandas. O terceiro período (tecnológico) produziu a megametrópole e integrou o capital rural, agrícola, urbano, de Estado e o internacional (Santos, 1978).

Para se compreender o processo de construção do espaço, é necessário reconhecer as forças produtivas e o modo de relação do Homem com a Natureza (H/N). O espaço, inicialmente, era "coi sa em si", depois a relação $\mathrm{H} / \mathrm{N}$ passou a ser histórica, e com o entendimento da epistemologia genética, via teoria construtivista, o Sujeito "Homem" e o Objeto "Natureza" passaram a ter uma "configuração combinante", sendo admitida por Smith (1988) como um processo vital de "metabolismo com a natureza".
Nas cidades moleculares a relação $\mathrm{H} / \mathrm{N}$ visava cada vez mais à mais-valia através do trabalho dividido, sendo o capital acumulado e concentrado nas mãos de poucos. Na megametrópole a exploração passou a ser realizada pelo capital de grupo, com máquina produzindo máquina e desemprego em massa, e o capital foi centralizado integrando a economia mundialmente. No processo de mundialização da economia, o capital além da função de uso passa à função de troca. Assim torna-se capaz de criar demanda em territórios móveis, através do capital móvel, onde e quando Ihe convém. Neste contexto a periferia deixa de ser somente a colonial ou a próxima do capital fixo, passando a ser também periferia de mercado. É aí que a informação e a demanda construída (efeito demonstração) passam a ser armas fundamentais do capital móvel no processo de acumulação, concentração e centralização econômica.

Para Smith, uma estratégia adotada visando à sobrevivência do capitalismo é a desvalorização do espaço construído em escalas urbana, regional e global. Os resultados da globalização da economia são: a) sociais, empobrecimento de muitos devido ao enriquecimento de poucos; b) econômicos, desenvolvimento de algumas áreas e subdesenvolvimento de outras; e, c) geo-econômicos, com domínio global da natureza, agora socialmente construída. Mas esta mundialização é perversa, pois renuncia à vocação de servir a sociedade da espécie humana (Guattari, 1990).

Com a industrialização (produção de bens por máquina) e a mecanização (produção de máquina por máquina) o capital tornou-se cada vez mais acumulado, concentrado e centralizado nas mãos de instituições internacionais. Este processo, comandado pelo capital através de grupos financeiro-industriais, excluíu, cada vez mais, grande contigente da população humana de: a) ter qualidade de vida dígna (água, esgoto, alimentação, educação, saúde, segurança, etc); b) poder consumir, embora seja esta uma das suas funções na nova ordem econômica mundial; e, c) exercer a cidadania. Portanto, a globalização da economia e do poder (via controle da informação) acabou (re)produzindo misérias coletivas, processos coletivos de doenças endêmico-epidêmicas em grupos particulares (Castellanos, 1987); e alienação em massa (Guattari, 1988).

Esta forma de organização dos meios de produção, da organização social do espaço e do controle do capital possibilitam a (re)instalação de velhas doenças endêmicas principalmente em periferias urbanas (leishmaniose, 
malária, cólera, esquistossomose, dengue, etc.); aparecimento de novas doenças típicas de grandes aglomerados populacionais (AIDS, poliomielite, meningite, etc.); aumento da mortalidade por causas externas (doença e acidentes produzidos pelo desgaste no trabalho, acidentes de trânsito, risco químico-tecnológico, violência, loucura, etc.), além do aumento de doenças crônicas degenerativas em jovens (causas internas naturais).

Para compreendermos a ocorrência de doenças endêmicas no espaço urbano periférico de grandes centros urbanos como a esquistossomose na região metropolitana de Belo Horizonte, faremos uso do conceito de circuitos econômicos elaborado por Santos (1978). Isto se faz necessário para compreendermos melhor a contribuição atual de, i.e, 47 grupos de "sem terra" e agora "sem casa" (50-70 000 famílias) na instalação de novos focos da esquistossomose no espaço urbano da Grande- $\mathrm{BH}$, principal mente se considerarmos que a maioria destas famílias é de migrantes de áreas rurais endêmicas.

No período de modernização tecnológica, após duas guerras mundiais, a globalização da economia acabou produzindo dois circuitos econômicos. O tamanho das cidades, as relações de vizinhança, novos sistemas de transporte, atividades artesanais, números reduzidos de empregos em grandes centros urbanos, ausência de um comércio integrado, relações diretas indispensáveis entre indústrias, comércio e atacadistas são condições favoráveis para a informação e o consumo se tornarem meios fundamentais de transformação da economia deste período.

A difusão da informação e a centralização do capital definem novas formas de organização do espaço. O uso da informação, em especial pelo efeito demonstração da propaganda, passou a ter a função básica de reduzir demanda de produções locais e abrir mercado principalmente na massa de trabalhadores. A existência de uma massa de pessoas com baixos salários e uma pequena parcela com renda muito elevada, cria na sociedade urbana uma divisão entre aqueles que consomem bens e serviços e os que necessitam consumir também, mas não podem. Isto cria diferenças quantitativas e qualitativas no consumo:

“Essas diferenças são a causa e o efeito da existência da criação e manutenção, em grandes cidades, de dois circuitos de produção, distribuição e consumo de bens e serviços: o supe rior eo inferior" (Santos, 1978:33).

Os dois circuitos são produtos da modernização tecnológica, ambos se beneficiando de formas diferentes, onde o inferior é dependente do superior. O superior é constituído por bancos, comércio, indústria de exportação urbana moderna, serviços modernos, atacadistas e transportadores. O inferior por fabricantes com pouco capital, serviços elementares a varejo e pelo comércio informal.

O superior se caracteriza principalmente pela presença de capital intensivo e o inferior por trabalho intensivo. No inferior, a acumulação de capital não constitui a primeira preocupação, simplesmente visa sobreviver e assegurar a reprodução (uma das poucas acumulações do circuito inferior é a produção de biomassa; usada pelo circuito inferior para produção de órgãos, prostituição, exploração de fronteira como no caso do ouro na amazônia e narcotráfico) e eventualmente consumir produtos do circuito superior. O "lugar" do circuito inferior é na cidade grande e sua região; e o do superior é fora, podendo se articular com cidades e regiões distantes.

A existência dos dois circuitos na economia das cidades é resultado de um mesmo grupo de fatores: a) os dois circuitos têm a mesma origem, o mesmo conjunto de causas e são interligados; b) o circuito inferior é um fenômeno econômico não delimitado geograficamente e apresenta a condição de dependência de todo um sistema econômico; e que, c) não se pode falar da existência de um circuito inferior da economia urbana nos países desenvolvidos (Santos, 1978).

Para Yves Leloup (1970), apud Santos (1978), somente em Minas Gerais se admitem três circuitos econômicos na cidade: da classe privilegiada, média e popular; devido ao seu caráter cultural arcaico que interfere nos modos de consumo e valor de troca. Fora desta realidade admite-se que no Terceiro Mundo a tripolarização de classes nas cidades não implica números correspondentes de circuitos econômicos.

Mas qual operacionalidade desta categoria "circuitos econômicos" para compreender o processo de transmissão da esquistossomose no espaço urbano? Verifica-se que a ocorrência da endemia em $20 \%$ da população residente na periferia de Belo Horizonte não pode ser considerada igual a $20 \%$ da prevalência em residentes de áreas rurais, visto que no espaço urbano o indivíduo do circuito inferior, onde normalmente ocorre a endemia, tem maior mobilidade, chegando a trabalhar temporariamente até cem quilômetros distante do domicílio, em função da falta de emprego. Quase impossível acompanhar evolutivamente estes indivíduos como nas áreas rurais onde o endereço normalmente é fixo e a transmissão quase sempre 
peridomiciliar. Não será com a mesma metodologia rígida até então adotada pelos serviços verticais em áreas rurais (busca ativa) que se deve abordar a esquistossomose no espaço urbano, seja devido às novas características de movimentação da esquistossomose no território, dos indivíduos cada vez mais móveis no espaço urbano, seja devido aos próprios espaços sociais móveis destinados a assentamentos de grupos de risco de excluídos da função social de produzir e consumir. Portanto, há que fazer uso de instrumentais flexíveis dentro do pensamento epidemiológico para fazer frente às sócio-bio-diversidades onde ocorre a endemia.

\section{Discussão}

O modelo de desenvolvimento adotado no Brasil vem favorecendo a concentração de renda e a exclusão de grande parte da população brasileira do acesso aos bens de consumo coletivo, sendo responsável pelo aprofundamento das desigualdades sócio-econômicas verificadas tanto entre grupos populacionais, como entre regiões (CNRS, 1988). Ao longo dos anos, acumularam-se as conseqüências negativas deste modelo sobre as condições gerais de vida e saúde da população. Este modelo econômico agrava o desordenado processo de urbanização, cada vez mais em precárias condições de habitação, e deficientes sistemas de abastecimento de água e de sistemas de esgotos sanitários, fazendo com que a qualidade de vida na periferia dos centros urbanos não difira da rural, quando não é pior (Alma-Ata, 1978; Barbosa,1980; Laurell, 1983; Silva, 1985a).

O desequilíbrio entre a acumulação do capital na mão de países centrais, financiadores deste tipo de modelo econômico, e o agravamento da qualidade de vida nos países do terceiro mundo levaram-nos a adotar políticas de saúde estatizantes e de caráter compensatório.

No Brasil, foi com a implantação da República que se organizou efetivamente a saúde pública como instituição. Sua principal função era viabilizar a execução de projetos econômicos de interesse de grupos dominantes nacionais e internacionais (Luz, 1973).

Desta forma, assistimos, no início deste século, ao governo brasileiro se preocupar: com a ancilostomíase nas regiões cafeeiras de São Paulo (Merthy, 1983); com a febre amarela no Rio de Janeiro, para melhorar a imagem do país no exterior e não prejudicar as exportações; e ainda com o combate à malária em várias frentes de obras públicas, buscando evitar a perda de mão-de-obra (Barreto, 1967).
A esquistossomose não pode ser considerada exceção deste processo. Não é em vão que, apesar de descrita no Brasil por Pirajá da Silva em 1908, não tenha despertado, por parte de pesquisadores e do Estado, grande interesse até depois da Segunda Guerra Mundial (Silva, 1985b). Apesar de ser considerada uma das seis grandes endemias que afligem o mundo, afeta apenas aqueles que, por necessidade de trabaIho ou falta de opção de lazer, são forçados a contatos constantes com águas infestadas com cercárias. Assim, a distribuição da infecção na população se dá forçosamente com maior freqüência e gravidade em indivíduos que vivem em piores condições de vida (Pessoa, 1948; Barbosa \& Coelho, 1957; Kloetzel, 1963; Katz, 1980, 1986a; Menezes \& Coura, 1978).

Com o final da Segunda Guerra Mundial e a transformação nas relações econômicas dos países desenvolvidos com os subdesenvolvidos, a ordem colonialista começa a passar da dominação política para a econômica. Organizações internacionais assumem o papel de financiadoras dos países subdesenvolvidos e passam a financiar projetos a longo prazo (Rodrigues, 1979). No Brasil, o processo migratório que se observa no eixo Nordeste/ Sudeste em função da necessidade de braços nos centros urbanos em industrialização, altera o perfil epidemiológico nas regiões receptoras, fazendo emergir novos problemas de Saúde Pública (Pessoa, 1948; Barreto, 1967; Coura, 1967; Carvalheiro, 1983). Com este fluxo migratório, “o Sul Maravilha" recebe de 4,0 a 7,0\% dos nordestinos migrantes infectados pelo Schistosoma mansoni (Marques, 1985).

Este deslocamento de mão-de-obra de áreas rurais para centros industrializados, somados à ausência de projetos de urbanização na periferia de grandes cidades, acabou provocando ou intensificando o favelamento urbano com precárias condições sanitárias, e péssima qualidade de reprodução da vida. Não é de se admirar que doenças parasitárias e infecto-contagiosas aí se instalem e passem a se expandir, como sucedeu com a esquistossomose na periferia de São Paulo, tornando-se uma doença de caráter também urbano (Barreto, 1984, 1986) e merecendo o status de "Problema de Saúde Pública" (Silva, 1985a), assim como em Belo Horizonte, MG (Coura-Filho, no prelo).

A ascensão da esquistossomose de doença restritamente rural para doença urbana altera o interesse de pesquisadores e do Estado. Observa-se que, entre 1908 e 1939, foram publicados na literatura brasileira, 107 trabalhos sobre esquistossomose. Durante o período de 1940 a 1949, foram publicados 202 trabalhos, um nú- 
mero quase três vezes maior, para um período de tempo três vezes menor (Silva, 1985b).

Foi após 1950 que vários autores desenvolveram projetos de pesquisas em populações de áreas endêmicas brasileiras. O modelo epidemiológico, usado na grande maioria destes projetos, buscava estabelecer relações de causa/ efeito dentro da concepção ecológica da doença, seja visando conhecer a dinâmica da transmissão ou identificando medidas (ou metodologias para se definirem medidas adequadas em cada foco) no combate à doença, tais como: combate ao hospedeiro intermediário; evolução clínica nos infectados submetidos ou não ao tratamento específico; obtenção de esquistossomicidas eficientes que produzam o mínimo de efeitos colaterais, podendo ser usados em larga escala e administrados por auxiliares de saúde com pequena capacitação profissional.

Os conhecimentos específicos adquiridos nestes estudos, somados aos interesses dos órgãos internacionais em garantir o retorno de capital investido em projetos desenvolvimentistas no Brasil, encorajaram o governo brasileiro a implantar no Nordeste o Programa Especial de Controle da Esquistossomose (PECE, 1976), cujo benefício à população foi minimizar a gravidade da doença nos portadores de forma hepatoesplênica, e reduzir a carga parasitária nos indivíduos tratados em área endêmica, mesmo sujeitos à reinfecção (Katz, 1986a), embora possa não estar associado à queda da prevalência (Carmo, 1994).

Embora ciente de que a infecção pelo $\mathrm{S}$. mansoni tem, fundamentalmente, seus determinantes macroestruturais exigindo visão e intervenção macroepidemiológica (Barbosa, 1985), o "problema esquistossomose" só terá solução definitiva quando tomadas medidas estruturais e específicas (Arouca, 1978; Barbosa,1985). Entretanto, enquanto estas medidas estruturais não ocorrerem, medidas específicas podem e devem ser adotadas em áreas endêmicas podendo controlar a morbidade da doença.

Embora a WHO (1985) tenha preconizado a educação para a saúde e a participação comunitária como estratégia operacional no controle da endemia, no Brasil poucas são as experiências onde a população participou ativamente de ações de controle da endemia (Barbosa et al., 1971; Barreto \& Prata, 1969; CouraFilho et al., 1992). Sabidamente, o Programa Especial de Controle da Esquistossomose (PECE, 1976) desenvolvido no nordeste do Brasil deixou de ser um programa com medidas associadas (tratamento, controle de vetores, sanea- mento básico e educação sanitária com participação da comunidade), como proposto inicialmente. Caracterizou-se como um projeto de intervenção vertical (comunidade como objeto, decisões sobre a metodologia tomadas no nível de poder central, atividades executadas por agentes externos à comunidade e através de ações específicas) com o fornecimento do tratamento específico, muitas vezes, como única medida oferecida aos infectados.

Pesquisas operacionais sobre o controle da esquistossomose usando-se abordagens alternativas têm sido preteridas pelas pesquisas sobre o tratamento específico, os métodos de diagnósticos e a prometida vacina (Kloetzel, 1992). Embora a estratégia da municipalização de programas de controle tenha propiciado bons resultados (Coura-Filho et al., 1992), a sua viabilidade exige estruturação no setor saúde (Tauil, 1983), principalmente no repasse de recursos financeiros para o nível local, na capacitação técnica de recursos humanos locais (Oliveira-Júnior, 1990), na organização da sociedade para exercer o controle fiscal dos recursos públicos (Valla et al., 1993) e na definição dos papeis das instituições federais, estaduais e municipais (Campos, 1990 ; Dallari, 1985).

Com o novo papel do Estado dentro da nova ordem econômica mundial assistimos à redefinição das funções da Fundação Nacional de Saúde cabendo-Ihe gerenciar, racionalizar diretrizes visando ao controle. Assistimos assim ao repasse do compromisso do desenvolvimento das ações para o nível local.

Assim, o desenvolvimento de abordagens, incluíndo-se aspectos das especificidades da dinâmica de transmissão conforme modo de produção econômica e, conseqüentemente, conforme modo de vida dos expostos à infecção pelo S. mansoni (Barbosa, 1995), torna-se uma meta e um duplo desafio, por falta de metodologias de intervenção além do enfoque biológico e por não fazer parte da hegemonia bio-tecnológica já estabelecida no país por interesses médico-institucionais em que o ato médico legitima a medicalização da doença e o papel interventivo do Estado.

\section{Considerações finais}

Quando Durkeim (1987) sugeriu tratar o fato social como "coisa", embora não seja coisa-emsi, criou um artifício metodológico que lhe possibilitou avaliar os determinantes sociais da ocorrência do suicídio como externalidade de uma dada condição social mais isenta de subjetividades. Sugeriu assim considerar a deter- 
minação social da ocorrência individualizada, buscando validar as informações obtidas dos indivíduos e buscando compreender o seu processo social de determinação (Warriner, 1956 apud Ritzer 1975).

A consideração de Merton (1968) de que a própria função da repetição da ocorrência individual cria a "estrutura-funcionalista" e elimina a impregnação da subjetividade e, portanto, é da mesma natureza do fato social, contrapõe à de Ritzer e Durkeim quando estes defendem o caráter coercitivo da estrutura social sobre os indivíduos. Para estes, o fato social pode ter origem nos indivíduos, mas é de outra ordem devido à força que passa a exercer sobre os indivíduos quando toma o status de modo-de-vida de uma população em dada organização social.

Para Coleman (1980) "os métodos de pesquisas têm negl igenciado a estrutura e a social inter-relação entre indivíduos"quando considera apenas os indivíduos como unidade de análise. Isto produz apenas informações sobre a "psicologi a de agregados" e não informações sobre o processo de ocorrências, inter-relações de grupos de indivíduos propiciando uma visão alargada da estrutura que produz o fato social .

Já Parsons (1964) acusou Weber de privilegiar estudos sobre a subjetividade (religiosa), acusou Durkeim por procurar demarcar uma linha divisória entre indivíduos e sociedade, assim como Marx por considerar apenas a determinação da estrutura sócio-econômica , via capital ismo, sobre os indivíduos. Para Parsons, esta justaposição de níveis (individual, grupal e estrutural) exige elaboração de categorias que os intercepte, promovendo maior interação dos conhecimentos produzidos em cada nível.

Fazendo uma analogia topográfica grosseira, podemos considerar que a prática da epidemiologia no setor saúde vem vivendo o desafio de também criar categorias mediadoras entre os níveis indivídual, grupal e estrutural, de forma a produzir conhecimento novo na compreensão de processos que possibilite a intervenção. No caso da esquistossomose, os estudos descritivos propiciados pela epidemiologia clínica centrada em conhecimentos sobre a ocorrência do agravo à saúde do indivíduo somados ao poder explicativo da epidemiologia social exigem elaboração de abordagens operativas que incorporem informações advindas dos indivíduos e da sociedade, para se compreender melhor os processos de produção de doenças em grupos particulares.

As perspectivas do uso do referencial teórico sobre os processos de produção, distribuição e consumo debensem grandes centros urbanos em país em desenvol vimento como o Brasil exigem: a) experimentar, conforme realidade em estudo, a unidade espacial para análise: localidade, município, região, mesoregião, bacia hidrográfica, assim como definir indicadores que informem o nível de urbanização conforme modos de inserção da mão-de-obra no mercado de trabalho;

b) validação das informações produzidas em dados agregados.

Para tanto e visando fazer uso deste referencial para analisar a distribuição espacial da esquistossomose no espaço mineiro, consideraremos:

a) O atual projeto sócio-político do Estado de Minas para assistir grupos de risco para doenças de veiculação hídrica como a esquistossomose na região da Grande- $\mathrm{BH}$, considerando a política de saneamento a ser adotada no Estado, entendendo-se o saneamento como sendo a medida preventiva de maior impacto na transmissão da esquistossomose no que tange ao fornecimento de água potável intradomiciliar (Coura-Filho et al., 1996) e eliminação de dejetos (mas o projeto construído pela sociedade mineira e na Assembleia Legislativa engloba coleta de lixo, drenagens e risco tecnológico).

b) A necessidade de se criar indicadores para medir a morbidade da endemia, sem caracterização da forma clínica via palpação de fígado e baço (Carmo, 1994). Neste sentido, estamos verificando a possibilidade de uso do Índice Potencial de Contaminação (IPC) (Marçal Jr. et al., 1991) como indicador indireto com alto valor preditivo positivo para morbidade da endemia, utilizando dados secundários produzidos pela Fundação Nacional de Saúde, em Minas.

c) Compreender melhor o modo de vida de uma sociedade com história de economia agrícola. Oberva-se que a sociedade civil mineira vem apresentando mecanismos moduladores próprios (cultura, solidariedade, valores culturais arcaicos de origem na família, religiosidade etc.) para abordar o problema do abandono em massa de parte da população que não tem mais a função social de produzir com mão-deobra desqualificada e conseqüentemente tem reduzido poder de compra. 


\section{Agradecimentos}

Aos Profs. Paulo Chagastelles Sabroza e Frederico Simões Barbosa por terem colaborado nesta elaboração na disciplina "Determinação ambiental e social das endemias", oferecida na Ensp/Fiocruz.

\section{Referências}

ALMA ATA, 1978. Cuidados primários em saúde. Genebra: WHO-Unicef.

AROUCA, A. T., 1978. Análise dos determinantes das condições de saúde da população brasileira. In: Saúdee Medicina no Brasil. (R. Guimarães, org.), pp. 147-154. Rio de Janeiro: Ed. Graal.

BARBOSA, F. S. \& COELHO, M. V., 1957. Alguns aspectos epidemiológicos relacionados com a transmissão da esquistossomose em Pernambuco, Brasil. Publicações Avul sas do Centro de Pesquisas Aggeu Magal hães, 5:31-47.

BARBOSA, F. S., 1980. Considerações sobre métodos profiláticos no controle da esquistossomose e os cuidados primários de saúde. Ciência e Cultura, 32:1628-1632.

BARBOSA, F. S., 1985. A epidemiologia como instrumento de transformação. Cadernos de Saúde Pública, 1:137-139.

BARBOSA, F. S., 1995. Determination and control of schistosomiasis. Memórias do Instituto Oswaldo Cruz, 90:155-159.

BARBOSA, F. S.; PINTO, R. F. \& SOUZA, O., 1971. Control of schistosomiasis mansoni in a small northeast brazilian community. Transactions of the Royal Soci ety of Tropical Medicine and Hygiene, 65:206-213.

BARRETO, A. C. \& PRATA, A., 1969. Aplicação em massa de moluscicida pela população local em uma área endêmica de esquistossomose. Gazeta Médica da Bahia, 69:20-24.

BARRETO, M. L., 1984. Esquistossomose Mansônica: Distribuição da Doença e Organização Social do Espaço. Dissertação de Mestrado, Salvador: Faculdade de Medicina, Universidade Federal da Bahia.

BARRETO, L. C. 1986. Epidemiology of Urban Schistosomiasis Mansoni in Northeast Brazil. A Case Study in Santo Antonio de Jesus. Ph.D. Thesis, London: London School of Hygiene and Tropical Medicine, University of London.

BARRETO, M. P., 1967. Movimento migratório e sua importância na epidemiologia de doenças parasitárias no Brasil. Revista da Sociedade Brasileira de Medicina Tropical, 1:91-102.

BRADLEY, D. 1972. Regulation of Parasite Populations. Transactions of the Royal Society of Tropical Medicineand Hygiene, 66:697-709.

CAMPOS, G. W. S., 1990. Um balanço do processo de municipalização dos serviços de saúde no Brasil. Cadernos de Saúde Pública, 4:414-419.

CARM O, E. H., 1994. Esquistossomose Mansônica no Estado da Bahia Produção da Doença no Espaço e Medidas de Controle. Dissertação de Mestrado, Salvador: Faculdade de Medicina, Universidade Federal da Bahia.
CARVALHEIRO, J. R., 1983. Processo migratório e disseminação de doenças. In.: Texto de Apoio. Ciências Sociais, p. 29-55. Rio de Janeiro: APCEABRASCO.

CASTELLANOS, P. Z., 1987. Sobre el concepto de salud-enfermedad: un punto de vista epidemiológico. I Taller Latinoamericano de Medicina Social. Medelin. (mimeo.)

COLEM AN, J., 1980. Relation analysis: the study of social organization with survey methods. In.: Sociological Methods (Denzin, N., ed.), pp. 115-126. Chicago: Aldine.

CNRS (Comissão Nacional de Reforma Sanitária), 1988. Síntese da Coordenação dos Grupos técnicos como contribuição ao documento final a ser elaborado pela CNRS. Documento III. Brasília: CNRS.

COURA, J. R., 1967. O problema da doença de Chagas nos grandes centros urbanos, 1967. In.: Resumos do 30 Congresso da Sociedade Brasileira de Medicina Tropical, 3:28-32.

COURA-FILHO, P. Distribuição da esquistossomose no espaço urbano. 1: o caso da região metropolitana de Belo Horizonte (Minas Gerais-Brasil). Cadernos de SaúdePública, no prelo.

COURA-FILHO, P.; ROCHA, R. S.; LIMA e COSTA, M. F. F. \& KATZ, N.,1992. A municipal level approach to the management of schistosomiasis control in Peri-Peri, MG - Brazil. Revista do Instituto de Medicina Tropical deSão Paulo, 34:543-548.

COURA-FILHO, P.; ROCHA, R. S.; LAMARTINE, S. S.; REZENDE, D. F.; COSTA, J. O.; FARAH, M. W. \& KATZ, N., 1996. Control of Schistosomiasis mansoni in Ravena (Sabará, Minas Gerais-Brazil) thougth water supply and quadreanual treatment. Memórias do Instituto Oswaldo Cruz, 91: 659-664.

DALLARI, S. G., 1985. Municipalização dos Serviços de Saúde. Dissertação de Mestrado, São Paulo: Faculdade de Medicina, Universidade de São Paulo.

DURKEIM, E., 1897. O Suicídio. New York:Free Press.

GARCIA, B. R., 1986. Conceptos básicos para el estudio de sistemas complejos. In.: Los Problemas del Conocimiento y la Perspectiva Ambiental del De sarrollo, (E. Leff, org.), pp. 45-71. México, DF: Siglo XXI.

GUATTARI, F., 1988. As Três Ecologias. Rio de Janeiro: Ed.34.

GUATTARI, F., 1990. Caosmose. Rio de Janeiro: Ed. 34.

KATZ, N., 1980. Experiências com quimioterapia em grande escala no controle da esquistossomose no Brasil. Revista do Instituto de Medicina Tropical deSão Paulo, 22:40-51.

KATZ, N., 1986a. Possibilidade de controle da esquistossomose. Jornal Brasileiro de Medicina, 50:8588. 
KLOETZEL, K., 1963. A conveniência da quimioterapia da esquistossomose em populações em contínuo contato com focos. Revista do Instituto de Medicina Tropical de São Paulo, 5:106-110.

KLOETZEL, K., 1992. Ciência auto-sustentada: o caso da esquistossomose. Cadernos de Saúde Pública, 8:204-206.

LAURELL, A., 1983. Saúde doença como processo social. In: Medicina Social: aspectos Históricos e Teóricos. (E. D. Nunes, org.), pp. 133-158. São Paulo, Ed. Global.

LUZ, T. M., 1973. As Instituições Médicas no Brasil. Rio de Janeiro: Ed. Graal.

MARÇAL Jr., O.; PATUCCI, R. M. J.; DIAS, L. C. S. HOTTA, L. K. \& ETZEL., 1991. Schistosomiasis mansoni in area of low transmission. I. Impact of control measures. Revista do Instituto de Medicina Tropical deSão Paulo, 33:83-90.

MARQUES, A.C., 1985. O controle das grandes endemias em 1984. Revista Brasileira de Malariologia eDoenças Tropicais, 37:77-92.

MATURANA, H. R., 1974. The organization of the living: a teoria of the living organization. Cibernetics Forum. Santiago (mimeo.).

MENEZES, A. P. \& COURA, J. R., 1978. Índice de transmissão da esquistossomose mansoni na cidade de Riachuelo, Sergipe. Revista da Sociedade Brasileira de Medicina Tropical, 13:21-24.

MERTHY, E. E., 1983. A Emergência das Práticas Sanitárias no Estado de São Paulo. Dissertação de Mestrado, São Paulo: Faculdade de Medicina, Universidade de São Paulo.

MERTON, R., 1968. Manifest and latent function. In.: On Theoretical Sociology (J. Neil, org.), pp. 73138. New York: Free Press.

OLIVEIRAJÚNIOR, M., 1990. Administração de recursos humanos: um obstáculo à municipalização dos serviços de saúde? Saúde em Debate, 28:4155.

PARSONS, T., 1964. Levels of organization and the mediation of social interation. Sociological Inquiry, 34:207-220.

PESSOA, J. B., 1948. Grandes endemias. Arquivo de Higienee Saúde Pública, 13:5-18.

PIRAJÁ DA SILVA, M. P., 1908. A esquistossomose na Bahia. Arquivo sobre Parasitologia, 13:281-300.

PECE (Programa Especial de Controle da Esquistossomose no Brasil), 1976. Brasília: Conselho de Desenvolvimento Social.
RITZER, G., 1975. Sociology: a multiple paradigm science. The American Sociologist, 10:156-167.

RODRIGUES, B., 1979. Fundamentos de Administração Sanitária. Brasília: Conselho de Desenvolvimento Social (mimeo.).

ROSICKY, B., 1987. Natural foci of diseases. In: Infections Diseases, Their Evolution and Erradication. (Cockburn, A., ed.), pp. 108-125. Springfield: Charles C. Thomas.

SABROZA, P. C., 1992. Espaço e produção de endemias. In: II Taller Latino-Americano de Medicina Social. Caracas: Universidad Central de Venezuela (mimeo.).

SANTOS, M., 1978. Os dois circuitos da economia urbana dos países subdesenvolvidos. In.: O Espaço Dividido (Santos, M., org), pp. 21-64. Rio de Janeiro: Livraria Francisco Alves.

SANTOS, M. L., 1978. Esquistossomose Mansoni: Estudo da Morbidade e Interferência da Terapêutica Específica em uma Área Endêmica. Dissertação de Mestrado, Rio de Janeiro: Faculdade de Medicina, Universidade Federal do Rio de Janeiro.

SILVA, L. J., 1985a. Crescimento urbano e doença: a esquistossomose no município de São Paulo. Revista de Saúde Pública, 19:1-7.

SILVA, L.J., 1985b. A construção de um problema de saúde pública: a esquistossomose no Brasil. Ciência eCultura, 38:509-513.

SMITH, N., 1988. Desenvolvimento Desigual: Natureza, Capital e a Produção do Espaço. Rio de Janeiro: Ed. Bertrand Brasil.

STARK, E., 1977. The epidemic as a social event. International Journal of Health Service, 7:681-705.

TAUIL, P. L., 1983. Controle de endemias: rede básica ou orgãos verticais? Saúde em Debate, 14:48.

TOGNONI, G., 1993. Epidemiología comunitaria. Apuntes para una nueva epidemiología. Salud y Sociedad, 10:4-10.

VALLA, V. V.; CARVALHO. M. \& ASSIS, M., 1993. Partici pação popular e os serviços de saúde: o controle social como exercício decidadania. Rio de Janeiro: ABRASCO/PARES.

WARRINER, C., 1956. Groups are real: a reafirmation. American Sociology Review, 21:519-554.

WHO (World Health Organization), 1985. Schistosomiasis Control. Technical Report Series, 728, Genebra: WHO. 